\title{
Sustainability of the Peritoneal Dialysis-First Policy in Hong Kong
}

\author{
Agnes Shin-Man Choy Philip Kam-Tao Li \\ CUHK Carol \& Richard Yu PD Research Center, Department of Medicine and Therapeutics, Prince of Wales Hospital, \\ Chinese University of Hong Kong, Hong Kong, SAR, China
}

\section{Key Words}

Peritoneal dialysis · PD-first policy · End-stage renal disease

\section{Abstract}

In Hong Kong, the average annual cost of haemodialysis (HD) per patient is more than double of that of peritoneal dialysis (PD). As the number of patients with end-stage renal disease (ESRD) has surged, it has posed a great financial burden to the government and society. A PD-first policy has been implemented in Hong Kong for three decades based on its cost-effectiveness, and has achieved successful outcomes throughout the years. A successful PD-first policy requires medical expertise in PD, the support of dedicated staff and a well-designed patient training programme. Addressing patients' PD problems is the key to sustainability of the PD-first policy. In this article, we highlight three important groups of patients: those with frequent peritonitis, ultrafiltration failure or inadequate dialysis. Potential strategies to improve the outcomes of these groups will be discussed. Moreover, enhancing HD as back-up support and promoting organ transplantation are needed in order to maintain sustainability of the PD-first policy.

(c) 2015 S. Karger AG, Basel

\section{Introduction}

The incidence of end-stage renal disease (ESRD) in Hong Kong in 2012 was 165 per million population, while the prevalence of ESRD was 1,192 per million population. The prevalence has risen significantly from that of 965 per million population in Hong Kong in 2005 [1, 2]. Dialysis is the lifeline for the majority of patients with ESRD, and the pattern of use of dialysis modalities varies greatly among countries. In Hong Kong, with its peritoneal dialysis (PD)-first policy, $72.9 \%$ of the dialysis population was treated with PD in 2012, the highest in the world [1].

\section{PD-First Policy in Hong Kong}

Maintenance haemodialysis (HD) was established in Hong Kong in 1969. Intermittent PD was introduced in the same year. The use of PD remained limited until 1980, when continuous ambulatory peritoneal dialysis (CAPD) was introduced. After CAPD had been shown to be a cost-effective therapeutic modality for treating ESRD,

\section{KARGER 125}

(c) 2015 S. Karger AG, Base

$0253-5068 / 15 / 0404-0320 \$ 39.50 / 0$ 
its use dramatically increased in many hospitals in Hong Kong. With the establishment of the Central Renal Committee in 1985, the planning and policy-making for the renal service in Hong Kong became standardized. On the basis of cost-effectiveness, the Committee promoted PD as the first-line dialysis modality for all patients with chronic kidney disease who require dialysis therapy, and this also marked the beginning of the PD-first policy. Under this policy, all patients requiring dialysis therapy are treated with PD first unless medical contraindications exist [3-5]. All patients with chronic kidney disease who require dialysis will be introduced to both $\mathrm{PD}$ and $\mathrm{HD}$ during pre-dialysis education, but the Hong Kong Hospital Authority will only reimburse patients for HD if they have medical contraindications for PD. Patients can choose to have $\mathrm{HD}$ first according to their personal preference, but they will have to bear the HD costs on their own.

\section{Why PD First?}

\section{Patient Survival}

Many studies have shown a significant association between survival advantage and receiving PD in the initial period of dialysis therapy [3,6-9]. To eliminate the confounding factor of potential selection bias for acutely ill patients who started dialysis urgently, one study investigated only incident patients with at least 4 months of pre-dialysis care and those who started dialysis treatment on an elective basis in the outpatient setting. The study found no difference in survival between patients treated with PD and HD [10]. Another study from the US Renal Data System found that the mortality rates for HD patients have declined very little in the US over the past decade, while the mortality rates for PD patients have declined continuously over time. There was no significant difference in the risk of death between those treated with HD and those treated with PD in the 20022004 period (hazard ratio, 1.03; 95\% confidence interval, 0.99-1.06) [10]. On the other hand, a recent systemic review found no evidence-based arguments in favour or against a particular dialysis modality as the first-choice treatment in patients with diabetes and ESRD [11].

\section{Residual Renal Function}

Previous studies have showed a more rapid decline in residual renal function (RRF) after commencement of HD compared with after commencement of PD $[12,13]$.
The early survival benefit of PD may be related to better preservation of RRF compared with HD. The postulated mechanisms for superior performance of PD in preserving RRF include greater haemodynamic stability, less ischaemic kidney insult and lack of inflammatory mediators generated by the extracorporeal HD circuit. Accumulating evidence showed that RRF contributes significantly to the overall health and survival benefit of dialysis patients [14-16].

\section{Infection Issues}

With extensive use of the disconnect and double bag system, PD patients in Hong Kong have a very low peritonitis rate. According to the Hong Kong Renal Registry, the PD peritonitis rate has improved from 1 per 25 patient months in 2001 to 1 per 35 patient months in 2011 [5]. A similar phenomenon was also observed in Australia and New Zealand with the PD peritonitis rate improving from 0.63 episodes per patient year in 2003 and 2004 to 0.43 episodes per patient year in 2011 [17]. In addition, it has been demonstrated that overall infection rates between HD and PD patients were similar (HD 0.77/year vs PD 0.86/year, $\mathrm{p}=0.24$ ). HD patients had an especially high risk of bacteremia in the first 90 days, whereas the risk of peritonitis for the PD cohort was not different over time. These results suggest that the PD catheter tends to be as problem-free as the fistula [18].

\section{How to Sustain the PD-First Policy in Hong Kong}

The rapidly expanding dialysis population represents a public health challenge that the current availability of donor kidneys for organ transplantation cannot meet. The number of patients requiring dialysis in the Hong Kong Hospital Authority system keeps growing steadily every year [5]. With the PD-first policy in Hong Kong, the growth of the PD population is much faster than for the patient population using other modes of renal replacement therapy. Despite the increasing prevalence of chronic kidney disease, a relatively constant successful PD outcome has been achieved in Hong Kong. Our previous cohort study of 328 incident CAPD patients recruited in the Prince of Wales Hospital between 1 January 2000 and 31 December 2004 showed that the 2-year patient survival was $91 \%$ and technique survival was $82 \%$ (fig. 1) [2]. Even for elderly patients ( $>65$ years old), analysis in our centre showed excellent 2- and 5-year technique survival of $84.0 \%$ and $45.7 \%$, respectively (fig. 2) [19]. 
Fig. 1. Patient and technique survival of 328 incident CAPD patients recruited in the Prince of Wales Hospital between 1 January 2000 and 31 December 2004. From Li and Szeto [2].
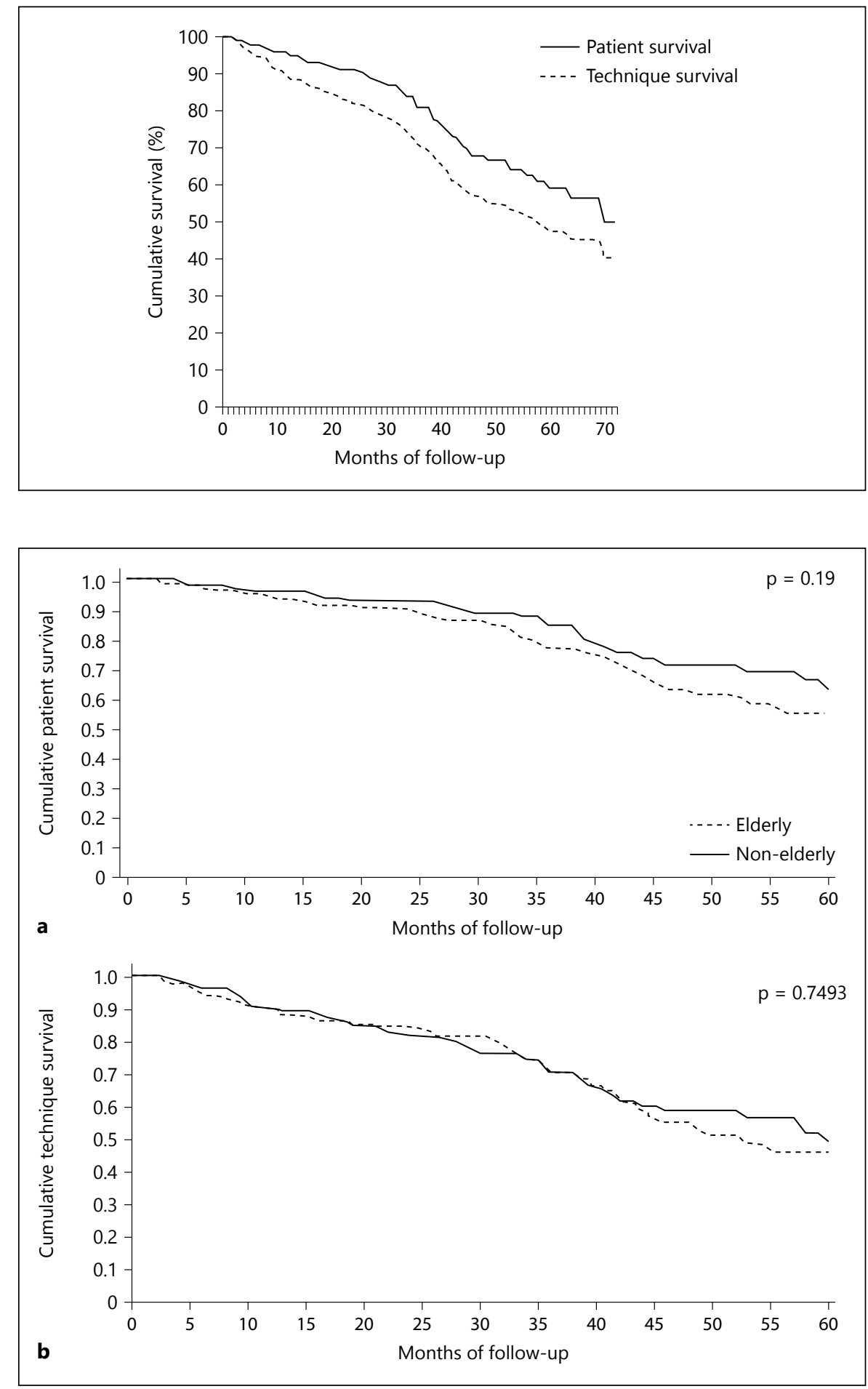

Fig. 2. Kaplan-Meier analysis of patient survival (a) and technique survival (b) for elderly and control patients on CAPD. From Li et al. [19]. 


\section{Frequent Peritonitis}

The ability to preserve peritoneal membrane integrity is one of the keys to the success of PD. Double bag systems brought about a significant improvement in peritonitis rates. Nevertheless, mounting evidence showed a decline only in organisms such as coagulase-negative staphylococci that are less likely to cause technique failure. On the other hand, Gram-negative organisms and extended spectrum beta-lactamase-producing bacteria have been recognized as important causes of technique failure [20, 21 ]. For each peritonitis episode, a root cause analysis should be done to determine the aetiology, and whenever possible, an intervention directed against any reversible risk factors should be made to prevent another episode. Possible etiologies included touch contamination, exit site infections or transmural migration (constipation or colitis). Identification of aetiology may involve a review of the patient's technique. If needed, retraining by experienced PD nurses should be performed [22, 23]. Early catheter removal is also encouraged to prevent relapsing peritonitis, refractory peritonitis, fungal peritonitis and refractory catheter infections. Preservation of the peritoneum should always be the main focus of therapy. Delayed catheter removal would lead to further peritoneal membrane damage and eventually permanent membrane failure [23]. In Hong Kong, Tenckhoff catheter insertion and removal are usually performed by nephrologists in most centres. This also helps in reducing the waiting time for surgical consultations and interventions, and facilitates timely management by well-trained nephrologists who are experts in Tenckhoff catheter management.

\section{Ultrafiltration Failure}

Conventional glucose-based PD fluids are bio-incompatible because of their high glucose and lactate concentrations, low $\mathrm{pH}$ and presence of glucose degradation products (GDP). Long-term use of conventional PD fluids in patients undergoing PD could lead to progressive damage of the peritoneal membrane, eventually resulting in PD failure [24]. Multiple studies have demonstrated that the prescription of neutral $\mathrm{pH}$, lactate-buffered, low GDP solution in PD patients was associated with a higher peritoneal membrane solute transport rate and a lower peritoneal ultrafiltration failure rate [25-27]. The use of biocompatible PD solution may also have the benefits of preserving RRF and reducing peritonitis rates [27].

Moreover, increasing diffusive transport of low molecular weight solutes was observed in patients treated with PD for $\geq 4$ years, leading to decreased net ultrafiltration of glucose-based solutions [28]. The increased num- ber of peritoneal blood vessels leads to increased vascular surface area and hence rapid dissipation of the osmotic gradient with glucose-based solutions. Icodextrin, a polyglucose preparation, is an iso-osmolar solution and induces ultrafiltration by its oncotic effect. The oncotic effect and the associated ultrafiltration by icodextrin are more sustained than with dextrose. The increase in ultrafiltration also enhances the convective transport of low molecular weight proteins. With the use of icodextrin, it can help to improve the volume status of PD patients and also lead to better preservation of peritoneal membrane function compared with dextrose [29].

\section{Inadequate Dialysis}

Adequacy of dialysis should be interpreted clinically rather than by targeting only solute and fluid removal. Clinical assessment should include peritoneal and renal clearances, nutritional status, acid-base balance, calcium phosphate haemostasis, haemoglobin concentration and responsiveness to erythropoietin therapy. For patients with signs and symptoms suggestive of under-dialysis, after ensuring good compliance to PD, a trial of increasing dialysis such as increasing frequencies or volume of each exchange should be provided even if $\mathrm{Kt} / \mathrm{V}$ urea is well above the minimal target [30]. However, if the problem persists, conversion to HD is warranted.

\section{Enhancing HD Support}

With the increasing number of PD patients in hospitals in Hong Kong, the capacity for HD must be enhanced in order to support patients who have problems with PD. As mentioned before, patients with frequent or refractory peritonitis require early catheter removal. These patients need to be put on temporary HD after catheter removal is performed. For patients with ultrafiltration failure and inadequate dialysis despite optimizing the PD regime, conversion to long-term HD will be required. Early referral to a urologist or vascular surgeon should be arranged to shorten the waiting time for arteriovenous access creation and maturation.

Under the Central Renal Committee of the Hong Kong Hospital Authority, PD patients are classified as high-risk PD patients if they have any one of the following: frequent peritonitis ( $>2$ times/year), inadequate ultrafiltration or inadequate dialysis. We hope to gradually reduce the high-risk $P D$ patient population to less than $5 \%$ of the total. In order to accommodate the growing demand for HD, the Hong Kong Hospital Authority has collaborated with the qualified community $\mathrm{HD}$ centres to provide options for patients to receive HD in the community 
under the Haemodialysis Public Private Partnership Programme. This also enhances collaboration between public hospitals and the community HD centres. As of February 2014, of 1,250 HD patients in Hong Kong, more than $230(>18 \%)$ were recruited into the programme to receive $\mathrm{HD}$ treatment in the community. In addition to expanding the inpatient HD facilities, Hong Kong is also using the Nocturnal Home Haemodialysis Programme to increase the number of patients who can be put on HD, especially for those who are found to be high-risk $\mathrm{PD}$ patients $[5,31,32]$.

\section{Promoting Organ Donation}

Another way to deal with the increasing demand of the dialysis population is to promote organ donation. For most patients with kidney failure, kidney transplantation has the greatest potential for restoring a healthy and productive life. However, because of the shortage of donor kidneys, each year only a small percentage of dialysis patients can receive one. Various organ donation promotion programmes have been arranged, including exhibitions, parades, talks and press conferences via the mass media. The aim is to raise public awareness of kidney diseases and promote organ donation. Hopefully, by increasing the number of kidney donors, more ESRD patients on dialysis therapy would be able to undergo kidney transplantation, offering them a better life and reducing their anxiety and concerns during the long wait for a kidney transplant [33].

\section{Conclusion}

In summary, as a home-based therapy, $\mathrm{PD}$ can improve patient survival, preserve RRF and lower infection risk in patients with ESRD while at the same time reducing financial stress to the government because of its cost-effectiveness. These are the reasons why the PD-first policy was implemented initially and why it is still practiced in Hong Kong today. The success of the PD-first policy requires the support of dedicated staff and well-designed patient training programmes. The dialysis centres have the important role of fostering expertise and experience in PD patient management. To ensure the sustainability of the PD-first policy, problems with $\mathrm{PD}$ also need to be addressed, including frequent peritonitis, ultrafiltration failure and dialysis adequacy. Enhancing HD support as back-up and promoting organ donation are necessary to meet the demands of the current rapidly growing dialysis population.

\section{Acknowledgements}

This study was supported in part by the CUHK Richard Yu PD Research Fund.

\section{Disclosure Statement}

The authors declare no conflicts of interest in relation to this work.

\section{References}

1 United States Renal Data System, 2014 Annual Data Report: Epidemiology of Kidney Disease in the United States. National Institutes of Health, National Institute of Diabetes and Digestive and Kidney Diseases, Bethesda, MD, 2014.

2 Li PK, Szeto CC: Success of the peritoneal dialysis programme in Hong Kong. Nephrol Dial Transplant 2008;23:1475-1478.

-3 Li PK, Chow KM: Peritoneal dialysis-first policy made successful: perspectives and actions. Am J Kidney Dis;62:993-1005.

4 Li PK, Chow KM: How to have a successful peritoneal dialysis program. Perit Dial Int 2003;23(suppl 2):S183-S187.

5 Leung CB, Cheung WL, Li PK: Renal registry in Hong Kong-the first 20 years. Kidney Int Suppl 2015;5:33-38.

6 Liem YS, Wong JB, Hunink MG, de Charro FTh, Winkelmayer WC: Comparison of hemodialysis and peritoneal dialysis survival in the Netherlands. Kidney Int 2007;71:153-158.

7 Sanabria M, Muñoz J, Trillos C, Hernández G, Latorre C, Díaz CS, Murad S, Rodríguez K,
Rivera A, Amador A, Ardila F, Caicedo A, Camargo D, Díaz A, González J, Leguizamón $\mathrm{H}$, Lopera P, Marín L, Nieto I, Vargas E: Dialysis Outcomes in Colombia (DOC) study: a comparison of patient survival on peritoneal dialysis vs hemodialysis in Colombia. Kidney Int Suppl 2008;73:S165-S172.

8 McDonald SP, Marshall MR, Johnson DW, Polkinghorne KR: Relationship between dialysis modality and mortality. J Am Soc Nephrol 2009;20:155-163.

\9 Weinhandl ED, Foley RN, Gilbertson DT, Arneson TJ, Snyder JJ, Collins AJ: Propensitymatched mortality comparison of incident hemodialysis and peritoneal dialysis patients. J Am Soc Nephrol 2010;21:499-506.

10 Quinn RR, Hux JE, Oliver MJ, Austin PC, Tonelli M, Laupacis A: Selection bias explains apparent differential mortality between dialysis modalities. J Am Soc Nephrol 2011;22: 1534-1542.

11 Couchoud C, Bolignano D, Nistor I, Jager KJ, Heaf J, Heimburger O, Van Biesen W: Dialysis modality choice in diabetic patients with end-stage kidney disease: a systematic review of the available evidence. Nephrol Dial Transplant 2015;30:310-320.

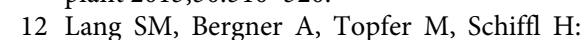
Preservation of residual renal function in dialysis patients: effects of dialysis-techniquerelated factors. Perit Dial Int 2001;21:52-57.

13 Jansen MA, Hart AA, Korevaar JC, Dekker FW, Boeschoten EW, Krediet RT; NECOSAD Study Group: Predictors of the rate of decline of residual renal function in incident dialysis patients. Kidney Int 2002;62:10461053.

14 Szeto CC, Wong TY, Chow KM, Leung CB, Li PK: Are peritoneal dialysis patients with and without residual renal function equivalent for survival study? Insight from a retrospective review of the cause of death. Nephrol Dial Transplant 2003;18:977-982.

15 Bargman JM, Thorpe KE, Churchill DN: Relative contribution of residual renal function and peritoneal clearance to adequacy of dialysis: a reanalysis of the CANUSA Study. J Am Soc Nephrol 2001;12:2158-2162. 
16 Li PK, Chow KM, Wong TY, Leung CB, Szeto CC: Effects of an angiotensin-converting enzyme inhibitor on residual renal function in patients receiving peritoneal dialysis. A randomized, controlled study. Ann Intern Med 2003;139:105-112.

17 Cho Y, Johnson DW: Peritoneal dialysis-related peritonitis: towards improving evidence, practices, and outcomes. Am J Kidney Dis 2014;64:278-289.

18 Aslam N, Bernardini J, Fried L, Burr R, Piraino $\mathrm{B}$ : Comparison of infectious complications between incident hemodialysis and peritoneal dialysis patients. Clin J Am Soc Nephrol 2006;1:1226-1233.

19 Li PK, Law MC, Chow KM, Leung CB, Kwan BC, Chung KY, Szeto CC: Good patient and technique survival in elderly patients on continuous ambulatory peritoneal dialysis. Perit Dial Int 2007;27(suppl 2):S196-S201.

20 Szeto CC, Chow KM: Gram-negative peritonitis - the Achilles heel of peritoneal dialysis? Perit Dial Int 2007;27(suppl 2):S267-S271.

-21 Szeto CC, Chow VC, Chow KM, Lai RW, Chung KY, Leung CB, Kwan BC, Li PK: Enterobacteriaceae peritonitis complicating peritoneal dialysis: a review of 210 consecutive cases. Kidney Int 2006;69:1245-1252.

22 Piraino B, Bernardini J, Brown E, Figueiredo A, Johnson DW, Lye WC, Price V, Ramalakshmi S, Szeto CC: ISPD position statement on reducing the risks of peritoneal dialysis-related infections. Perit Dial Int 2011;31:614-630.
23 Li PKT, Szeto CC, Piraino B, Bernardini J, Figueiredo AE, Gupta A, Johnson DW, Kuijper EJ, Lye WC, Salzer W, Schaefer F, Struijk DG: Peritoneal dialysis-related infections recommendations: 2010 update. Perit Dial Int 2010;30:393-423.

24 Chaudhary K, Khanna R: Biocompatible peritoneal dialysis solutions: do we have one? Clin J Am Soc Nephrol 2010;5:723-732.

25 Williams JD, Topley N, Craig KJ, Mackenzie RK, Pischetsrieder M, Lage C, PasslickDeetjen J: The Euro-Balance Trial: the effect of a new biocompatible peritoneal dialysis fluid (balance) on the peritoneal membrane. Kidney Int 2004;66:408-418.

26 Kim S, Oh J, Kim S, Chung W, Ahn C, Kim SG, Oh KH: Benefits of biocompatible PD fluid for preservation of residual renal function in incident CAPD patients: a 1-year study. Nephrol Dial Transplant 2009;24: 2899-2908.

27 Johnson DW, Brown FG, Clarke M, Boudville $\mathrm{N}$, Elias TJ, Foo MW, Jones B, Kulkarni H, Langham R, Ranganathan D, Schollum J, Suranyi MG, Tan SH, Voss D: The effect of low glucose degradation product, neutral $\mathrm{pH}$ versus standard peritoneal dialysis solutions on peritoneal membrane function: the balANZ trial. Nephrol Dial Transplant 2012; 27:4445-4453.
28 Mateijsen MA, van der Wal AC, Hendriks PM, Zweers MM, Mulder J, Struijk DG, Krediet RT: Vascular and interstitial changes in the peritoneum of CAPD patients with peritoneal sclerosis. Perit Dial Int 1999;19: 517-525.

29 Krediet R, Mujais S: Use of icodextrin in high transport ultrafiltration failure. Kidney Int 2002;S53-S61.

30 Lo WK, Bargman JM, Burkart J, Krediet RT, Pollock C, Kawanishi H, Blake PG: Guideline on targets for solute and fluid removal in adult patients on chronic peritoneal dialysis. Perit Dial Int 2006;26:520-522.

31 Li PKT, Cheung WL, Lui SL, et al: Increasing home-based dialysis therapies to tackle dialysis burden around the world: a position statement on dialysis economics from the 2nd Congress of the International Society for Hemodialysis. Nephrology (Carlton) 2011;16: 53-56.

32 Tang HL, Wong JH, Poon CK, Tang CM, Chu KH, Lee W, Fung SK, Chau KF, Li CS, Tong KL: One year experience of nocturnal home haemodialysis with an alternate night schedule in Hong Kong. Nephrology (Carlton) 2011;16:57-62.

33 Li PKT, Chu KH, Chow KM, Lau MF, Leung CB, Kwan BC, Tong YF, Szeto CC, Ng MM: Cross sectional survey on the concerns and anxiety of patients waiting for organ transplants. Nephrology (Carlton) 2012;17:514518 